\title{
Fetal and placental size and risk of hypertension in adult life
}

\author{
D J P Barker, A R Bull, C Osmond, S J Simmonds
}

\section{Abstract}

Objective-To study the effect of intrauterine growth and maternal physique on blood pressure in adult life.

Design-A follow up study of infants born 50 years previously whose measurements at birth were recorded in detail.

Setting-Preston, Lancashire.

Subjects - 449 Men and women born in hospital in Preston during 1935-43 and still living in Lancashire.

Main outcome measures-Placental weight, birth weight, and blood pressure at age 46 to 54 years.

Results - In both sexes systolic and diastolic pressures were strongly related to placental weight and birth weight. Mean systolic pressure rose by $15 \mathrm{~mm} \mathrm{Hg}$ as placental weight increased from $\leqslant 1 \mathrm{lb}$ $(0.45 \mathrm{~kg})$ to $>1.5 \mathrm{lb}$ and fell by $11 \mathrm{~mm} \mathrm{Hg}$ as birth weight increased from $\leqslant 5.5 \mathrm{lb}$ to $>7.5 \mathrm{lb}$. These relations were independent so that the highest blood pressures occurred in people who had been small babies with large placentas. Higher body mass index and alcohol consumption were also associated with higher blood pressure, but the relations of placental weight and birth weight to blood pressure and hypertension were independent of these influences.

Conclusions-These findings show for the first time that the intrauterine environment has an important effect on blood pressure and hypertension in adults. The highest blood pressures occurred in men and women who had been small babies with large placentas. Such discordance between placental and fetal size may lead to circulatory adaptation in the fetus, altered arterial structure in the child, and hypertension in the adult. Prevention of hypertension may depend on improving the nutrition and health of mothers.

\section{Introduction}

The geographical pattern of mortality from cardiovascular disease in England and Wales closely resembles the pattern of maternal and neonatal mortality earlier in this century. ${ }^{12}$ In the past maternal mortality was high in places where women had poor physique and health ${ }^{3}$ and neonatal mortality was high where many babies had low birth weights. ${ }^{4}$ There is therefore a geographical association between poor maternal physique and health, poor fetal growth, and high death rates from cardiovascular disease.

A recent follow up study gave the first indication that a similar association exists for individual people. Among 5654 men born in Hertfordshire during 1911-30 those who had the lowest weights at birth and at the age of 1 year subsequently had the highest death rates from ischaemic heart disease. ${ }^{5}$ Differences in death rates according to early weight were large and were reflected in differences in life expectancy.

These findings raise the question of what processes link intrauterine life with risk of cardiovascular disease.
Blood pressure, a known risk factor for both ischaemic heart disease and stroke, is one possibility. Geographical differences in the incidence of cardiovascular disease in Britain correlate with differences in mean blood pressure of men and women. ${ }^{6}$ The persistence of rank order of blood pressure among people examined at intervals (tracking) has been repeatedly observed in longitudinal studies of children and adults. ${ }^{78}$ Factors in adult life that are known to influence blood pressure, such as body mass, alcohol consumption, and intake of salt, account for only a small part of the differences in pressure between individual people and populations. ${ }^{9}$

To study the relation between intrauterine growth and blood pressure in adults we examined a group of middle aged men and women whose measurements at birth had been recorded in unusual detail.

\section{Subjects and methods}

During 1935-43 a standardised record was kept for each woman admitted to the labour ward at Sharoe Green Hospital, Preston, Lancashire. The record contained details of the mother's previous pregnancies and external measurements of her pelvis, including the conjugate diameter (distance between the symphysis pubis and the fifth lumbar vertebra). The baby's birth weight, placental weight, length from crown to heel, and head circumference were also recorded. Weights were measured in pounds $(1 \mathrm{lb}=0.45 \mathrm{~kg})$ and lengths and head circumferences in inches $(1 \mathrm{inch}=2.54 \mathrm{~cm})$. Measurements had often been rounded and we therefore preserved the original units.

Our first sample was of 259 men and women born during 1935-40 and the second, which was taken to test the strong associations found in the first, was of 190 people born up to 1944 . The total sample came from 1298 singleton infants who were born to married mothers during 1935-43 and had complete records. We traced $1122(86 \%)$ through the NHS central register; 503 were living in Lancashire at addresses known to their general practitioners and were asked to take part in the study. Of these, $449(89 \%)$ agreed to do so.

Each subject was visited at home by one of four fieldworkers. The fieldworkers had not seen the obstetric data recorded for the subjects. Height was measured with a portable stadiometer and weight with a portable seca scale. Blood pressure and pulse rate were measured with an automated recorder (Dinamap) when the subjects were sitting down. Readings were taken on the left arm with the cuff size recommended for the arm circumference. The room temperature was also measured. The subjects, who remained seated, were asked about their medical history, current medication, smoking habits, alcohol consumption, and family history of cardiovascular disease. Alcohol consumption was converted to the total number of grams consumed each week. According to criteria in general use, consumption was categorised as low (men $\leqslant 168 \mathrm{~g}$, women $\leqslant 112 \mathrm{~g}$ ), moderate $(\leqslant 280 \mathrm{~g}, \leqslant 168 \mathrm{~g}$ ), and high $(>280 \mathrm{~g},>168 \mathrm{~g}){ }^{10}$ The father's occupation was 
used to define social class at birth, ${ }^{11}$ and current social class was derived from the subject's or her husband's occupation. After the interview the subject's blood pressure was measured again. The average of the two readings was used in the analysis. Before starting the study the procedures for measurements were standardised and the fieldworkers trained. No important interobserver variation was found during checks at intervals throughout the survey, in which repeat measurements were made on subjects selected from outside the study population.

\section{Results}

Systolic and diastolic blood pressures were strongly related to placental weight. In the first sample of 259 subjects the mean systolic pressure was $148 \mathrm{~mm} \mathrm{Hg}$ in those who had had placental weights of $\leqslant 1.5 \mathrm{lb}$ and $159 \mathrm{~mm} \mathrm{Hg}$ in those who had had weights $>1.5 \mathrm{lb}$ (difference $11,95 \%$ confidence interval, 4 to 18 ). A second sample of 190 subjects was taken to test this relation. Among them the mean systolic pressure was $148 \mathrm{~mm} \mathrm{Hg}$ for those whose placentas had weighed $\leqslant 1.5 \mathrm{lb}$ and $155 \mathrm{~mm} \mathrm{Hg}$ for those whose placentas had weighed $>1.5 \mathrm{lb}(7,0$ to 14$)$. When the two samples were combined the difference was 9 (4 to 14).

Because the two samples were similar we combined them for further analysis. The ages of the 236 men and 213 women ranged from 46 to 54 (mean 50 ) years. The mean (SD) systolic pressures were $154(20) \mathrm{mm} \mathrm{Hg}$ in men and 146 (23) $\mathrm{mm} \mathrm{Hg}$ in women, and the mean diastolic pressures were 89 (11) $\mathrm{mm} \mathrm{Hg}$ in men and 83 (11) $\mathrm{mm} \mathrm{Hg}$ in women. Systolic pressure rose by $1.3 \mathrm{~mm} \mathrm{Hg}$ for each year of age, and diastolic pressure rose by $1.0 \mathrm{~mm} \mathrm{Hg}$. We adjusted all pressures to age 50 . One fieldworker took $55 \%$ of the blood pressure measurements, and the small, non-significant differences in the mean values obtained by the three other fieldworkers were adjusted for. The mean placental weight for the men was $1.4 \mathrm{lb}$ and for the women $1.3 \mathrm{lb}$; mean birth weights were 7.0 and $6.9 \mathrm{lbs}$ respectively. Placental weight and birth weight were strongly correlated $(r=0.52)$.

Table I shows the mean systolic and diastolic pressures according to placental weight and birth weight. For each birth weight systolic and diastolic pressures rose with placental weight, and for each placental weight both pressures fell with increasing birth weight. Simultaneous adjustment by regression for systolic pressure showed a rise of $15 \mathrm{~mm} \mathrm{Hg}$ ( $95 \%$ confidence interval 8 to 23 ) from adults who had
TABLE I-Mean systolic and diastolic blood pressures $(\mathrm{mm} \mathrm{Hg})$ of men and women aged 46 to 54 according to placental weight and birth weight. Number of subjects in parentheses

Placental weight $(\mathrm{lb})$

\begin{tabular}{lccccc} 
Birth weight (lb) & $\leqslant 1 \cdot 0$ & $-1 \cdot 25$ & $-1 \cdot 5$ & $>1 \cdot 5$ & All \\
\cline { 2 - 6 }$\leqslant 5 \cdot 5$ & $152(26)$ & $154(13)$ & $153(5)$ & $206(1)$ & $154(45)$ \\
$-6 \cdot 5$ & $147(16)$ & $151(54)$ & $150(28)$ & $166(8)$ & $151(106)$ \\
$-7 \cdot 5$ & $144(20)$ & $148(77)$ & $145(45)$ & $160(27)$ & $149(169)$ \\
$>7 \cdot 5$ & $133(6)$ & $148(27)$ & $147(42)$ & $154(54)$ & $149(129)$ \\
\hline All & $147(68)$ & $149(171)$ & $147(120)$ & $157(90)$ & $150(449)$ \\
\hline \multicolumn{5}{c}{ Diastolic pressure } \\
$\leqslant 5 \cdot 5$ & 84 & 87 & 87 & 97 & 86 \\
$-6 \cdot 5$ & 84 & 88 & 85 & 93 & 87 \\
$-7 \cdot 5$ & 84 & 84 & 84 & 90 & 85 \\
$>7 \cdot 5$ & 78 & 85 & 85 & 88 & 86 \\
\hline All & 84 & 86 & 85 & 89 & 86 \\
\hline
\end{tabular}

TABLE II - Mean systolic pressure ( $\mathrm{mm} \mathrm{Hg}$ ) among adults according to birth weight, placental weight, and sex. Number of subjects in parentheses

\begin{tabular}{|c|c|c|c|c|c|}
\hline \multirow[b]{2}{*}{ Birth weight (lb) } & \multicolumn{5}{|c|}{ Placental weight (lb) } \\
\hline & $\leqslant 1 \cdot 0$ & $-1 \cdot 25$ & $-1 \cdot 5$ & $>1.5$ & All \\
\hline $\begin{array}{l}\leqslant 6.5 \\
-7.5 \\
>7.5 \\
\end{array}$ & $\begin{array}{l}150 \\
152 \\
132 \\
\end{array}$ & $\begin{array}{c}\text { Men } \\
159 \\
154 \\
149 \\
\end{array}$ & $\begin{array}{l}152 \\
147 \\
153 \\
\end{array}$ & $\begin{array}{l}161 \\
164 \\
154 \\
\end{array}$ & $\begin{array}{l}155(79) \\
154(85) \\
153(72)\end{array}$ \\
\hline All & $149(26)$ & $155(88)$ & $151(66)$ & $158(56)$ & $154(236)$ \\
\hline $\begin{array}{l}\leqslant 6 \cdot 5 \\
-7 \cdot 5 \\
>7 \cdot 5\end{array}$ & $\begin{array}{l}150 \\
141 \\
133\end{array}$ & $\begin{array}{l}\text { Women } \\
143 \\
141 \\
148\end{array}$ & $\begin{array}{l}149 \\
143 \\
139\end{array}$ & $\begin{array}{l}191 \\
155 \\
152\end{array}$ & $\begin{array}{l}149(72) \\
144(84) \\
145(57)\end{array}$ \\
\hline All & $146(42)$ & $143(83)$ & $143(54)$ & $157(34)$ & $146(213)$ \\
\hline
\end{tabular}

had placental weights of $\leqslant 1 \mathrm{lb}$ to those who had had weights $>1.5 \mathrm{lb}$ and a fall of $11 \mathrm{~mm} \mathrm{Hg}$ (3 to 19) from those who had had birth weights of $\leqslant 5.5 \mathrm{lb}$ to those who had weighed $>7.5 \mathrm{lb}$. Similar patterns were found in men and women (table II). When birth weights were grouped at intervals of $0.5 \mathrm{lbs}$ from $\leqslant 5.0 \mathrm{lb}$ to $>9.5 \mathrm{lb}$ systolic pressure in each group was higher in those who had had placental weights $>1.5 \mathrm{lb}$. The figure shows the simultaneous effect of placental weight and birth weight on systolic pressure. The highest pressures were among people who had been small babies with large placentas and the lowest were among people who had been large babies with small placentas. Multiple regression analysis for diastolic pressure showed a rise of $6 \mathrm{~mm} \mathrm{Hg}$ (2 to 10) from subjects who had had placental weights of $\leqslant 1$ lb to those who had had weights $>1.5 \mathrm{lb}$, and a fall of $2 \mathrm{~mm} \mathrm{Hg} \mathrm{(}-2$ to 7 ) from subjects who had had birth weights of $\leqslant 5.5 \mathrm{lb}$ to those who had weighed $>7.5 \mathrm{lb}$.

In both men and women mean systolic and diastolic pressures were higher with higher body mass index (weight $/$ height ${ }^{2}$ ). When the sexes were combined those in the lowest quarter of the distribution $\left(\leqslant 24 \mathrm{~kg} / \mathrm{m}^{2}\right)$ had a mean systolic pressure of $145 \mathrm{~mm} \mathrm{Hg}$ and mean diastolic pressure of $84 \mathrm{~mm} \mathrm{Hg}$ and those in the highest quarter $\left(>28 \mathrm{~kg} / \mathrm{m}^{2}\right)$ had mean pressures of $156 \mathrm{~mm} \mathrm{Hg}$ and $87 \mathrm{~mm} \mathrm{Hg}$ respectively. Among the 78 subjects with moderate or high intakes of alcohol, the mean systolic pressure was $4 \mathrm{~mm} \mathrm{Hg}$ higher than that among those with low intakes $(-1$ to 10$)$ and the mean diastolic pressure was also $4 \mathrm{~mm} \mathrm{Hg}$ higher (2 to 7). Blood pressure was not consistently related to smoking or room temperature. Adjusting for body mass index and intake of alcohol made little difference to the values in table $\mathrm{I}$. The simultaneous trends in systolic pressure with placental weight, birth weight, body mass index, intake of alcohol, and sex were calculated by multiple regression. Table III shows that the size of the trends in systolic pressure with placental weight 
TABLE III-Mean change $(95 \%$ confidence interval) in systolic pressure associated with body mass index, alcohol consumption, and sex

\begin{tabular}{cc}
\hline & $\begin{array}{c}\text { Systolic pressure } \\
\text { (mm } \mathrm{Hg})\end{array}$ \\
\hline $\begin{array}{c}\text { Placental weight } \\
\text { (lb): }\end{array}$ & \\
$\leq 1$ & \\
$-1 \cdot 25$ & $4(-2$ to 10$)$ \\
$-1 \cdot 5$ & $1(-5$ to 8$)$ \\
$>1 \cdot 5$ & $12(5$ to 20$)$ \\
Birth weight $(\mathrm{lb}):$ & \\
$\leqslant 5 \cdot 5$ & 0 \\
$-6 \cdot 5$ & $-5(-12$ to 3$)$ \\
$-7 \cdot 5$ & $-8(-15$ to -1$)$ \\
$>7 \cdot 5$ & $-10(-18$ to -2$)$ \\
Body mass index $\left(\mathrm{kg} / \mathrm{m}^{2}\right):$ \\
$\leq 24$ & 0 \\
-26 & $3(-2$ to 8$)$ \\
-28 & $3(-3$ to 8$)$ \\
$>28$ & $10(4$ to 15$)$ \\
Alcohol consumption: \\
Low & 0 \\
Moderate & $5(-2$ to 12$)$ \\
High & $5(-2$ to 12$)$ \\
Sex: & \\
Men & 0 \\
Women & $-6(-10$ to -2$)$ \\
&
\end{tabular}
placental weight, birth weight,

and birth weight was only slightly changed by adjustment for the three other variables. The findings for diastolic pressure were similar.

Thirty six of the subjects ( 21 men, 15 women) were being treated for hypertension. Table IV shows the relative risk of hypertension according to placental weight. Risks were estimated by odds ratios. The trend of increase in risk up to $3 \cdot 0$ was significant $(p=0 \cdot 01)$. There was no corresponding trend with birth weight. Table IV also shows the trend of increasing risk of hypertension defined by a systolic pressure $>160 \mathrm{~mm} \mathrm{Hg}$, which was found in 124 subjects (75 men, 49 women). Risk rose to 2.5 in those who had had the heaviest placentas and fell to 0.7 in those who had had the heaviest birth weights. With body mass index risk rose to $2 \cdot 3$ in those with values in the highest quarter.

The duration of gestation of 370 subjects could be estimated because the date of onset of the mother's last menstrual period had been recorded. The simultaneous trends in systolic pressure with placental weight, birth weight, length of gestation, and sex were calculated by multiple regression. Adjusting for gestation had little effect on the trends in systolic pressure with placental weight and birth weight (table

TABLE IV-Relative risk (95\% confidence interval) of being treated for hypertension or having a systolic pressure $>160 \mathrm{~mm} \mathrm{Hg}$ according to placental weight

\begin{tabular}{|c|c|c|c|c|}
\hline & \multicolumn{4}{|c|}{ Placental weight (lb) } \\
\hline & $\leqslant 1 \cdot 0$ & $-1 \cdot 25$ & -1.5 & $>1.5$ \\
\hline $\begin{array}{l}\text { Treated for hypertension }(n=36) \\
\text { Systolic pressure }>160 \mathrm{~mm} \mathrm{Hg}(n=124)\end{array}$ & $\begin{array}{l}1 \cdot 0 \\
1 \cdot 0\end{array}$ & $\begin{array}{l}1 \cdot 3(0 \cdot 4 \text { to } 5 \cdot 0) \\
1 \cdot 1(0 \cdot 6 \text { to } 2 \cdot 2)\end{array}$ & $\begin{array}{l}2 \cdot 4(0 \cdot 7 \text { to } 8 \cdot 9) \\
1 \cdot 2(0 \cdot 6 \text { to } 2 \cdot 5)\end{array}$ & $\begin{array}{l}3 \cdot 0(0 \cdot 8 \text { to } 11 \cdot 3) \\
2 \cdot 5(1 \cdot 2 \text { to } 5 \cdot 0)\end{array}$ \\
\hline
\end{tabular}

TABLE V-Mean change (95\% confidence interval) in systolic placental weight, birth weight. length of gestation, and sex

\begin{tabular}{lc} 
& $\begin{array}{c}\text { Systolic pressure } \\
\text { (mm Hg) }\end{array}$ \\
\hline $\begin{array}{l}\text { Placental weight (lb): } \\
\leqslant 1\end{array}$ & 0 \\
$-1 \cdot 25$ & $4(-2$ to 10$)$ \\
$-1 \cdot 5$ & $3(-4$ to 9$)$ \\
$>1 \cdot 5$ & $13(6$ to 21$)$ \\
Birth weight $(\mathrm{lb}):$ & \\
$\leqslant 5 \cdot 5$ & 0 \\
$-6 \cdot 5$ & $-4(-11$ to 4$)$ \\
$-7 \cdot 5$ & $-7(-15$ to 0$)$ \\
$>7 \cdot 5$ & $-10(-18$ to -2$)$ \\
Length of gestation & \\
(weeks): & 0 \\
$\leqslant 37$ & $-2(-9$ to 5$)$ \\
38 & $-2(-8$ to 3$)$ \\
39 & $-3(-9$ to 20$)$ \\
40 & $1(-6$ to 7$)$ \\
41 & $-1(-8$ to 6$)$ \\
$\geqslant 42$ & 0 \\
Sex: & $-7(-11$ to -3$)$ \\
Men &
\end{tabular}

V). Findings for diastolic pressure were similar. Length of gestation had no significant effect on either systolic or diastolic pressure.

The parity of all except nine mothers had been recorded. The systolic and diastolic pressures were related to placental weight in the children of the 353 primiparous mothers and the 87 multiparous ones (table VI). The difference in systolic pressures associated with placental weights $>1.5 \mathrm{lb}$ and $\leqslant 1.5 \mathrm{lb}$ was, however, greater in children of multiparous mothers. The inverse relation between pressure and birth weight was similar in children of primiparous and multiparous mothers.

All except 25 of the subjects could be classified according to social class at birth. In each social class there was a similar relation between systolic and diastolic pressures and placental weight (table VI). The results were similar when subjects were classified by current social class. In each social class there was also an inverse relation between pressure and birth weight.

Ninety four subjects said that their mothers had suffered from high blood pressure. These subjects' mean systolic pressure was $8 \mathrm{~mm} \mathrm{Hg}$ higher than that of the other subjects ( 3 to 13 ). The 58 subjects whose fathers had high blood pressure did not themselves have higher pressure, the difference from the other

TABLE VI-Mean systolic pressure $(\mathrm{mm} \mathrm{Hg})$ by parity and social class at birth and at age $46-54 .{ }^{\star}$ (Number of subjects in parentheses)

\begin{tabular}{lccc}
\hline & \multicolumn{3}{c}{ Placental weight (lb) } \\
\cline { 2 - 4 } & $\leqslant 1 \cdot 5$ & $>1 \cdot 5$ & All \\
\hline Parity: & $149(289)$ & $156(64)$ & $150(353)$ \\
$\quad$ Primiparous & $146(65)$ & $162(22)$ & $150(87)$ \\
$\quad$ Multiparous & $147(101)$ & $156(20)$ & $148(121)$ \\
Social class at birth: & $150(143)$ & $160(36)$ & $152(179)$ \\
$\quad$ I, II, III Non-manual & $148(94)$ & $155(30)$ & $150(124)$ \\
$\quad$ III Manual & $147(140)$ & $158(37)$ & $149(177)$ \\
IV, V & $150(131)$ & $154(34)$ & $151(165)$ \\
$\quad$ Iocial class at age 46-54: & $149(86)$ & $164(18)$ & $152(104)$ \\
$\quad$ III Manual & & & \\
$\quad$ IV, V & & & \\
\hline
\end{tabular}

^Parity of nine mothers not known birth and of three at age 46-54 not birth and of
classifiable.
IV, pressure associated with subjects being $-1 \mathrm{~mm} \mathrm{Hg}$ ( -7 to 5$)$. The mean placental weight of those whose mothers had high blood pressure was the same as that of the remainder at $1 \cdot 3 \mathrm{lb}$.

The mean circumference of the head at birth was 13.6 (SD 0.7) inches and the mean length was 20.4 $(1 \cdot 1)$ inches. Circumference of the head and length increased with birth weight. For any birth weight head circumference increased with placental weight whereas length decreased, so that the ratio of length to head circumference was strongly inversely related to placental weight. A $0.5 \mathrm{lb}$ increase in placental weight was associated with a decrease of $0.23 \mathrm{SD}(\mathrm{p}<0.01)$ in the ratio of length to head circumference.

Birth weight increased progressively with mothers' external conjugate diameter. The mean birth weight rose from $6.6 \mathrm{lb}$ among those with mothers with conjugates of $\leqslant 7 \cdot 25$ inches to $7 \cdot 5$ among those with mothers with conjugates $>8.25$ inches. Placental weight was not related to the external conjugate diameter independently of birth weight.

\section{Discussion}

We found that blood pressure and risk of hypertension among men and women aged around 50 are predicted by a combination of placental weight and birth weight. The highest blood pressures and risk of hypertension were among people who had been small babies with large placentas. Because the strong relation with placental weight was unexpected we repeated our first study and found similar results. Higher body mass with higher blood pressure, in agreement with the results of many other studies, ${ }^{9}$ but the relation of placental weight and birth weight to blood pressure and hypertension was independent of these influences and stronger (table III). Two routine measurements taken at birth were better predictors of blood pressure than any current measurement. To our knowledge this has not been observed before.

The 449 people in our study had been born in hospital. In Preston 50 years ago only a small proportion of babies were born in hospital, and most of them were firstborn children. The correspondence attached to the maternity records showed that many mothers booked a bed at an early stage of pregnancy. Medical problems were not an important reason for the women choosing to have their babies in hospital. As the analysis was based on comparisons within the sample bias would have been introduced only if the relations of blood pressure to placental weight and birth weight were different among people born in and outside hospital. Such bias seems unlikely because we showed that the relations were similar for first and later born children (table V). The similar results seen in people in each social class, whether defined at birth or currently, suggest that the findings were not biased by selective migration according to socioeconomic state. Weights recorded routinely at birth, especially placental weights, are subject to error. This would tend to reduce the strength of relations with later blood pressure, as would the inclusion of people whose blood pressures were being lowered by treatment (tables I-III).

In the only previous follow up study relating birth weight to blood pressure in adults there were no data on placental weight. ${ }^{12}$ There was a small difference of $2 \mathrm{~mm} \mathrm{Hg}$ in mean systolic pressure between the 36 year old adults in the highest and lowest thirds of the distribution of birth weight. The differences by birth weight among all subjects in table I are consistent with this. The large, independent and opposing effects of a fall in systolic pressure of $10 \mathrm{~mm} \mathrm{Hg}$ associated with increasing birth weight and a rise of $12 \mathrm{~mm} \mathrm{Hg}$ (table index and alcohol consumption were also associated 
III) associated with increasing placental weight were not seen when all pressures at a given birth weight are combined.

The strength and gradation of the relation between blood pressure and placental weight and birth weight make it less likely that it depends on some unknown confounding variable. Findings in children, among whom there are fewer possible confounding variables, support this. Two recent surveys in Britain of children aged 5 to 10 found that blood pressure was inversely related to birth weight. ${ }^{12} 13$ These associations in children are, however, weaker than those we found in adults.

Our data point to a possible mechanism for the relation between placental weight and blood pressure. Studies of fetal blood flow in animals have shown that in response to hypoxia there is a redistribution of fetal cardiac output, which favours the perfusion of the brain. ${ }^{14}$ In our data greater placental weight at any birth weight was associated with a decrease in the ratio of length to head circumference. This disproportionate growth is consistent with diversion of blood away from the trunk in favour of the brain. Reduced blood flow to the trunk induced in a fetus that is small in relation to its placenta could have irreversible consequences, perhaps by influencing arterial structure.

There is evidence in animals and humans that changes in the haemodynamic load in early life can alter the structure and compliance of larger arteries. ${ }^{16}$ In rats made hypertensive four weeks after birth the wall of the aorta thickens rapidly. This partly reverses if the hypertension is relieved. In young children born with a single umbilical artery the common iliac that gave rise to it is elastic whereas the other, which had lower blood flow, is thin walled and muscular. ${ }^{17}$ These differences are reflected in differences in compliance, as measured by Doppler ultrasonography. ${ }^{18}$ Compliance determines pulse pressure, and changes in pulse pressure produce changes in vessel wall scleroprotein, which in turn change compliance. This feedback could perpetuate high systolic pressure from infancy to old age. This is, however, only one possible mechanism by which fetal circulatory changes could change the structure of blood vessels in adults. ${ }^{19}$

Mothers' blood pressures are related to those of their children,,$^{20}$ and it could be argued that placental weight is linked to adult blood pressure through a genetic mechanism that determines both the blood pressure of the child and the growth of the placenta. The blood pressure of pregnant women at their first antenatal attendance was studied in 5161 consecutive first births in Oxford during 1987-8. The pressures were unrelated to either birth weight or placental weight (C W G Redman, unpublished data). In our survey people who reported that their mothers had high blood pressure had higher blood pressure themselves, but their placental weights were similar to those of the remainder. People who reported that their fathers had high blood pressure did not themselves have higher blood pressure.

A question arising from our findings is, What environmental influences act on the mother and determine placental weight and birth weight? In particular, what determines the discordance between placental and fetal size which leads to high blood pressure? Little is known about maternal factors that influence placental growth. In our data the mothers' smoking habit and alcohol consumption were not recorded. The data show, however, that the mothers' external conjugate diameter is strongly related to birth weight. This is consistent with the known relation between maternal height and birth weight. ${ }^{21}$ A woman's physique depends partly on her nutrition in childhood. The nutrition of girls may therefore be linked to blood pressure in the next generation.
The customary explanation for differences in blood pressure is that they depend on the environment during adult life. ${ }^{22}$ Our findings, however, suggest that the intrauterine environment has a dominant effect on blood pressure. Research into the adult environment and hypertension has focused on salt. ${ }^{93}$ A recent cross cultural study in 52 centres concluded that lowering the daily intake of sodium from $170 \mathrm{mmol}$ to $70 \mathrm{mmol}$ corresponded to a $2 \mathrm{~mm} \mathrm{Hg}$ reduction in systolic blood pressure. ${ }^{9}$ This is a small effect compared with those associated with placental weight and birth weight, which range over $25 \mathrm{~mm} \mathrm{Hg}$ (table III). Differences of this order may have large effects on mortality from cardiovascular disease. Available data suggest that lowering the distribution of blood pressure among a population by $10 \mathrm{~mm} \mathrm{Hg}$ would correspond to a $30 \%$ reduction in total attributable mortality. ${ }^{24}$

The decrease in mortality from stroke in Britain during the past 40 years is consistent with past improvements in maternal physique and health. ${ }^{2}$ Reducing blood pressure in a population may partly depend on improving the environment of girls and women, including improving their nutrition. This will reduce discordance between placental and fetal growth, which leads in turn to circulatory adaptation in the fetus, altered arterial structure in the child, and hypertension and cardiovascular disease in the adult.

We thank Mrs F Foden and the medical records staff at Sharoe Green Hospital, who preserved the records and allowed us to use them; the staff at the NHS central register, Southport, and Lancashire Family Practitioner Committee; and general practitioners throughout the county who traced the subjects. Marie Ward and Margaret Kelly were fieldworkers.

1 Barker DJP, Osmond C. Infant mortality, childhood nutrition and ischaemic heart disease in England and Wales. Lancet 1986; i:1077-81.

2 Barker DJP, Osmond C. Death rates from stroke in England and Wales predicted from past maternal mortality. Br Med f 1987;295:83-6.

3 Campbell JM, Cameron D, Jones DM. Ministry of Health reports on public health and medical subjects, No 68. High maternal mortality in certain areas. London: HMSO, 1932

4 Local Government Board. Thirty-ninth annual report 1909-10. Supplement on infant and child mortality. London: HMSO, 1910.

5 Barker DJP, Winter PD, Osmond C, Margetts B, Simmonds SJ. Weight in infancy and death from ischaemic heart disease. Lancet 1989;ii:577-80.

6 Shaper AG, Pocock SJ, Walker M, Cohen NM, Wade CJ, Thomson AG. British regional heart study: cardiovascular risk factors in middle-aged men in 24 towns. Br Med F 1981;283:179-86.

7 de Swiet $M$, Fayers $P$, Shinebourne EA. Value of repeated blood pressure measurements in children - the Brompton study. Br Med F 1980;i: 1567-9.

8 Clarke WR, Schrott $\mathrm{H}$, Leaverton PE, Connor WE, Laver RM. Tracking of blood lipids and blood pressure in school age children: the muscatine study. Circulation 1978:58:626-34.

9 Intersalt Cooperative Research Group. Intersalt: an international study of electrolyte excretion and blood pressure. Results for 24 hour urinary sodium and potassium excretion. $\mathrm{BrMed}$ f 1988;297:319-28

10 Royal College of Physicians. A great and growing evil: the medical consequences of alcohol abuse. London: Tavistock Publications, 1987.

11 Office of Population Censuses and Surveys. Classification of occupations 1980. London: HMSO, 1980

12 Barker DJP, Osmond C, Golding J, Kuh D, Wadsworth MEJ. Growth in utero, blood pressure in childhood and adult life, and mortality from cardiovascular disease. Br Med f 1989:298:564-7.

13 Whin PH, Cook DG, Shaper AG. Early influences on blood pressure: study of children aged 5 to 7 years. Br Med $\mathcal{Y}$ 1989;299:587-91.

4 study of children a Dawes GS, Fishman AP, Hyman AI. Regional redistribution of blood flow in the mature fetal lamb. Circ Res 1967;21:229-35.

15 Rudolph AM. The fetal circulation and its response to stress. I Dev Physiol 1984;6:11-9.

16 Berry CL. Hypertension and arterial development: long-term considerations. Br Hearl F 1978;40:709-17.

17 Meyer WW, Lind J. Iliac arteries in children with a single umbilical artery structure, calcification and early atherosclerotic lesions. Arch Dis Child 1974;49:671-9.

8 Berry CL, Gosling RG, Laogun AA, Bryan E. Anomalous iliac compliance in children with a single umbilical artery. Br Heart F 1976;38:510-5.

19 Folkow B. Physiological aspects of primary hypertension. Physiol Rev 1982;62:347-504.

20 Zinner GH, Rosner B, Oh W, Kass EH. Significance of blood pressure in infancy, familial aggregation and predictive effect of later blood pressure. Hypertension 1985;7:411-6.

21 Butler N, Alberman ED. Second report of the 1958 British perinatal mortality survey. Edinburgh: Churchill Livingstone, 1969.

22 Elford J, Phillips A, Thomson AG, Shaper AG. Migration and geographic variations in blood pressure in Britain. Br Med $\mathcal{F}$ 1990;300:291-5.

23 Anotions. Diet and hypertension. [Editorial.] Lancet 1984;ii:671-3.

24 Rose G. Sick individuals and sick populations. Int $\mathcal{A}$ Epidemiol 1985;14:32.

(Accepted 23 May 1990 